\title{
Contribuições da escola para a (de)formação dos sujeitos surdos
}

\author{
Carla Biancha Angelucci \\ Renato Dente Luz
}

\begin{abstract}
Resumo
O artigo discute, a partir do diálogo entre materialismo histórico dialético e a psicanálise winnicottiana, as contribuições da escola para a constituição da identidade de sujeitos surdos. A análise de bibliografia pertinente apontou para a escassez de trabalhos que consideram a relação entre a escola e os processos de subjetivação dessas pessoas. Para compreender as discussões desse campo, foram realizadas reflexões sobre os fenômenos escolares contemporâneos à luz da Psicologia para uma Educação Formativa - e não deformadora - para todas e todos. Quanto à população surda, apesar de não haver consenso a respeito dos efeitos da escolarização em instituições inclusivas ou especializadas, concluiu-se que os profissionais da Educação precisam de liberdade e condições objetivas para criar/recriar espaços e estratégias de aprendizagem, com a finalidade de proporcionar aos educandos - e a si mesmos - experiências de relações mais horizontais com o outro, esteja ele marcado pela diferença linguística, sensorial, orgânica, etária, cognitiva ou étnica.
\end{abstract}

Palavras-chave: Psicologia escolar, surdo, subjetividade.

\section{School Contributions to the (de)formation of deaf individuals}

\begin{abstract}
In this article we discuss the school contributions to identity constitution of deaf people, based on a dialogue between dialectical and historical materialism and the winnicottian psychoanalysis. Bibliographic analysis relating to this matter indicated a lack of productions that consider the relation between school and deaf people subjectivity process. In order to comprehend discussions on this field, we propose some reflections on contemporary school phenomena by using a Psychology which seeks a Formative Education - and not a degenerate one - to All individuals. With regard to deaf people, although there is not an agreement over schooling effects into inclusive or special institutions, we conclude that school professionals must have liberty to create/recreate learning places and strategies. This will help to provide to students and teachers the experience of a horizontal relations with the Other, in spite of his or her different linguistic background, age group, cognitive or ethnic condition.
\end{abstract}

Keywords: School psychology, deaf, subjectivity.

\section{Contribuciones de la escuela para la (de)formación de los sujetos sordos}

\section{Resumen}

El artículo discute, a partir del dialogo entre materialismo histórico dialéctico y el psicoanálisis winnicottiano, las contribuciones de la escuela para la constitución de la identidad de sujetos sordos. El análisis de bibliografía pertinente señaló la escasez de trabajos que consideran la relación entre la escuela y los procesos de subjetivación de esas personas. Para comprender las discusiones de ese campo se realizaron reflexiones sobre fenómenos escolares contemporáneos bajo enfoque de la Psicología para una Educación Formativa - y no deformadora - para todas y todos. Sobre la población sorda, a pesar de no haber consenso al respecto de los efectos de la escolarización en instituciones de inclusión o especializadas, se concluye que los profesionales de la Educación necesitan libertad y condiciones objetivas para crear/recrear espacios y estrategias de aprendizaje, con la finalidad de proporcionar a los educandos - y a si mismos - experiencias de relaciones más horizontales con el otro, esté él marcado por la diferencia lingüística, sensorial, orgánica, etaria, cognitiva o étnica.

Palabras clave: Psicología escolar, sordo, subjetividad. 


\section{Introdução}

\section{A experiência cultural em que atualmente nos localizamos}

O objetivo do presente trabalho é refletir sobre as implicações da escola na constituição da subjetividade de pessoas surdas. Partimos, aqui, de uma Psicologia que encontra o homem no mundo para compreender tal constituição, afirmando, portanto, uma intrínseca relação com os processos sociais. Considerando o movimento dialético de progresso e regressão das condições de sustentação dos processos de humanização que caracterizam a História (Horkheimer \& Adorno, 1985), propomos um exercício de pensamento: o que comunica a instituição educacional à criança surda em relação à sua possibilidade de existir como sujeito?

Entendemos que a Educação é parte de nossos processos de socialização, sendo, portanto, uma das instituições que produz e reproduz relações sociais. As formas como ela se realiza, seus objetivos e as instituições responsáveis por sua objetivação articulam-se ao nosso modo de produção, à nossa forma de conceber e realizar a política, bem como às nossas aspirações de transformação da realidade social. Assim, a um só tempo, a Educação é instrumento de legitimação e perpetuação do instituído como também é depositária de anseios de ruptura com os processos de dominação e exclusão (Saviani, 2005). Por esse motivo, entendemos que os estudos sobre a escola, principal instituição responsável pela formalização dos processos educacionais, são essenciais em projetos que pretendem a transformação social de modo a nos aproximarmos da realização dos valores humanos, dos nossos sonhos - hoje, já bastante pálidos - de formação de um homem que possa constituir-se na direção de sua própria humanidade.

É esta a posição ético-política que orienta nossas escolhas teóricas.

Ao realizarmos um levantamento bibliográfico sobre surdez em periódicos nacionais por meio do portal Scielo, encontramos 85 trabalhos, dos quais apenas 18 fazem menção ao universo simbólico ou a aspectos psicológicos. Cabe ressaltar que, entre eles, a grande maioria refere-se a aspectos psicopatológicos ou à aquisição de habilidades cognitivas de pessoas surdas. Apenas dois trabalhos propõem-se a discutir aspectos ligados à identidade (Bueno, 1998; Dizeu \& Caporali, 2005), nos quais encontramos reflexões sobre o uso da língua de sinais como aspecto constituinte da identidade. Diferentes posicionamentos são considerados na relação entre cultura ouvinte e cultura surda, entretanto, a atenção ao tema é elemento basilar das discussões.

Encontramos ainda um artigo que discorre sobre as contribuições da Psicologia para o estudo da surdez (Bisol, Simioni, \& Sperb, 2008).

Não encontramos trabalhos recentes que, do ponto de vista da Psicologia, estudem escolarização e constituição da identidade surda, o que parece indicar que estudos de aproximação, como este que apresentamos, podem contri- buir para o aprofundamento da discussão do campo. Nossa busca aproxima-se das discussões de Bisol e cols. (2008), que realizou um amplo levantamento bibliográfico sobre o tema, concluindo que os estudos encontrados:

Revelam, por exemplo, uma tendência dos psicólogos brasileiros de optarem pelo modelo socioantropológico de surdez. Também mostram que a psicanálise está presente contribuindo com sua perspectiva para o debate numa área que até então ficava polarizada entre o modelo clínicoterapêutico e o modelo socioantropológico. O levantamento referente às temáticas eleitas pelos psicólogos brasileiros abre um campo amplo para se pensar no desenvolvimento desta área no país. Há, por exemplo, um foco significativo no estudo de processos que se situam na infância, com alguns trabalhos seguindo até a adolescência. As temáticas desenvolvidas precisam ser ainda discutidas considerandose as demais fases do desenvolvimento vital, incluindo estudos com surdos bebês e adultos. (s/p.)

Assim, este trabalho partirá de reflexões teóricas a respeito do tema, a fim de criar um campo de discussão que não se centre na surdez como patologia, nem nas particularidades do desenvolvimento do indivíduo surdo. Outrossim, desejamos apontar para as contribuições da Psicologia Escolar, que se compromete com a dimensão educacional do fenômeno humano, a fim de avançarmos na garantia de uma experiência escolar implicada com o respeito à diversidade humana. Diversidade esta, aqui, não tomada como ente abstrato, mas como experiência concreta entre sujeitos politicamente iguais.

Desde a elaboração da Declaração de Salamanca, em 1994, não cabe mais discutirmos se a Educação é direito ou não das pessoas com necessidades educacionais especiais - e, dentre elas, as pessoas surdas. A questão que se impõe, agora, no campo da Psicologia, refere-se à construção de um arcabouço teórico que fundamente intervenções comprometidas com a garantia de uma Educação conjunta para todas e todos ${ }^{1}$, de caráter emancipatório. Entendemos que tal Educação significa, necessariamente, respeito à diversidade de estilos cognitivos, pertencimentos étnicos, culturais, religiosos, condições orgânicas, etc.

Para tanto, não basta a garantia de matrícula escolar, pois já sabemos que a natureza da lógica sobre a qual a instituição educacional ergueu-se e mantém-se é meritocrática e excludente. Kupfer e Petri (2000) lembram-nos que o nascimento da escola cria, ao mesmo tempo, outro fenômeno: a criança escolar. Como discutem as autoras, quando nos perguntamos a respeito de quem frequentará a escola, estamos admitindo a existência de crianças escolarizáveis e não

1 Utilizaremos a expressão "todas e todos" quando nos referirmos à garantia do direito à Educação por entendermos que, apesar de não se tratar de questão aqui aprofundada, é essencial o estabelecimento de recorte de gênero para a compreensão das dificuldades de escolarização no Brasil, seja em relação à permanência escolar, seja em relação às queixas escolares (Carvalho, 2004). 
escolarizáveis. Resta, agora, relembrarmos quais os critérios utilizados ao longo de nossa história para responder a essa questão. Bueno (2004), Patto (2000a) e Jannuzzi (2004) são alguns dos vários autores que têm estudado profundamente a garantia do direito à Educação no Brasil. Esses autores colocam-nos frente a um aspecto tão básico a respeito da Educação para todas e todos, mas que teimamos em esquecer: desde sua origem, a escola, instituição social que é filha de seu tempo, não entende como escolarizáveis aqueles que são significativamente diferentes, seja devido à língua, à cultura, à condição socioeconômica, à imagem corporal ou à organização sensorial, entre outras condições. Tais autores lembram-nos que o acesso à educação formal esteve restrito aos filhos de famílias de classe média e alta até a década de 1970 (Patto, 2000a).

Analisando os efeitos da política de Educação Especial no Brasil das décadas de 1970, 80 e 90, Bueno (2004) concluiu que a ampliação de vagas para a população com deficiência proporcionada pelos Planos de Educação Especial não pode ser considerada expressiva: em 1974, eram 96.413 as pessoas com deficiência matriculadas, passando a 102.268 em 1981 e a 159.325 em 1987. Além disso, o autor evidencia que esse aumento não significou acréscimo de oferta de educação pública, dado que as matrículas na rede privada continuaram representando mais de $40 \%$ das vagas (pp. 118-120).

Enfim, são significativamente diferentes aqueles que não correspondem ao padrão hegemônico - e abstrato - vigente. É verdade que a empresa atual de inserir no texto da lei a obrigatoriedade de pensarmos a escolarização de cada segmento populacional que cuidadosamente excluímos ao longo da história de nossa Educação é um avanço sem precedentes. Reconhecermos o direito, por parte da população com diferenças significativas, à Educação é uma inegável conquista. Estamos, enfim, reconhecendo a legitimidade do direito: a escola pertence a todas e a todos. Mas hoje, passado o momento do reconhecimento dessa legitimidade, já podemos ir além e perguntar: que socialização oferecemos quando recebemos pessoas com deficiência em salas regulares do modo como temos recebido, ou seja, sem transformações substantivas da escola?

Como em todo processo social, elementos de regressão também são facilmente percebidos. Estudos como os de Angelucci (2002, 2009), Pereira e Nascimento (2006) e Góes e Laplane (2004) dedicam-se a compreender a forma como a política de inclusão tem se concretizado, tanto no âmbito da Educação Básica, quanto na Educação Infantil e de nível Superior. Tais pesquisas revelam que a Educação Inclusiva tem sido essencial para a garantia de matrícula escolar de pessoas significativamente diferentes, mas as condições estruturais, curriculares e atitudinais que garantiriam permanência e sucesso escolar ao alunado ainda estão longe de serem ofertadas, posto que implicam transformações na própria lógica educacional, que deve partir do reconhecimento da diversidade humana e do caráter excludente da organização do tempo, da apresentação dos conteúdos e da função da avaliação na escola. A partir destas considerações, entende- mos que pensar sobre a pergunta "quem tem ficado de fora do direito à escola" pode fazer-nos perceber a trajetória de nossa (des)humanização, abrindo-se, então, o campo para que outro caminho seja trilhado, em outra direção.

Se acompanharmos a concretização da política de inclusão no Estado de São Paulo, quase tudo indica que evoluímos a largos passos na direção contrária à de uma escola de qualidade para/com todas e todos (Patto, 2000b; Viégas \& Angelucci, 2006). Afinal, o que tem sido a política de inclusão? Uma política de continuidade do projeto educacional desde há muito em vigor no Brasil, ou seja, uma política de desconsideração do sujeito humano, do processo educacional democrático e conjunto, da garantia universal da apropriação dos saberes produzidos ao longo da nossa história.

Esse é um dos motivos pelos quais assistimos a uma onda conservadora por parte de muitos segmentos educacionais: inúmeros educadores têm batalhado há décadas pelo direito irrestrito à Educação, entre eles, muitos têm lutado pela Educação conjunta. Porém, dadas as angustiantes experiências recentes, é comum ouvirmos o retorno da velha conhecida justificativa para a segregação: "lá, na instituição especializada, saberão o que fazer com ele. Aqui não temos como dar conta".

Tais experiências e seus efeitos sobre aqueles que defendem os direitos sociais e os valores democráticos constituem importante aspecto a ser considerado pelos psicólogos comprometidos com a dimensão educacional dos processos de constituição do sujeito humano, pois nos alertam sobre o risco presente na adesão irrefletida, hoje tão corrente, à política de inclusão. Se, por um lado, sua difusão demonstra o reconhecimento do direito à Educação, por outro, é necessário enfatizar a atenção para o gesto de reificação ${ }^{2}$ do humano, ao se pretender abarcar necessidades e condições tão diversas sem uma crítica radical às condições concretas em que a vida humana se produz, reproduz e transforma. Daí o imperativo de pensarmos as transformações na instituição escolar como condição sine qua non para o exercício efetivo do direito.

Educação para/com todas e todos não pode significar homogeneização das necessidades e dos serviços, sob risco de tornar-se Educação para/com assujeitamento. Chamamos atenção, agora, para outro aspecto do fenômeno que discutimos: há uma estreita relação entre a forma como concebemos e realizamos um dos direitos sociais mais básicos e a produção de determinada subjetividade.

Este trabalho é, portanto, um gesto - digamos em maior conformidade com nosso tema -, um sinal que pretende contribuir com a resistência ao projeto globalizado de reificação hoje em vigor.

2 Entendemos, aqui, reificação no sentido adorniano, ou seja, como supressão da heterogeneidade, do não idêntico, em nome de uma pretensa identidade dos sujeitos que são objetificados, sob o pretexto de necessidade de tratamento uniforme das pessoas (Horkheimer \& Adorno, 1985). 
Segundo as estatísticas oficiais, no Brasil, há 25 miIhões de pessoas com deficiência, sendo que cerca de 66 mil são pessoas com perda auditiva. A respeito deste segmento populacional, o Ministério da Educação registra 52.566 matrículas, desde a Educação Infantil até o Ensino Superior (SEESP/MEC, 2007). Comunidades organizadas em torno da defesa de segmentos populacionais marcadamente desrespeitados, como os surdos, têm afirmado com convicção a impossibilidade de escolarização conjunta. Alguns dos argumentos: direito a uma língua integralmente acessível por meio da experiência visual e utilizável enquanto real instrumento de comunicação/diálogo, busca pela experiência subjetiva e coletiva da perda auditiva enquanto um traço diferencial e não demeritório, necessidade de construção e fortalecimento da identidade, entre outros. Assim, no caso desse segmento populacional, a história da Educação revela a marca de constantes impossibilidades de convivência com ouvintes, sob pena de perder o direito à sua forma comunicacional privilegiada, a língua de sinais, ou seja, sob pena de perder o direito à diferença e à construção coletiva, realizada pela comunidade surda nas últimas décadas, de uma forma de viver e organizar-se subjetivamente, incorporando a surdez como traço identitário.

\section{Psicologia, Educação e a pessoa surda precoce}

[...] O defeito mais grave com que nos defrontamos atualmente consiste em que os homens não são aptos à experiência, mas interpõem entre si mesmos e aquilo a ser experimentado aquela camada estereotipada a que é preciso se opor (Adorno, 2000, p. 148-9).

Nos últimos anos, tem havido no Brasil um esforço governamental que visa permitir a existência de uma escola que, efetivamente, seja para todas e todos. No entanto, a efetivação de tal política da igualdade de direitos pode tornarse reducionista e, consequentemente, desumanizadora, se não for capaz de atentar às diferentes expressões humanas advindas de uma diversidade maior do que a contemplada pelo termo "deficiente" ou qualquer outro termo generalista deste tipo.

A partir desta primeira questão, cabe, portanto, para além dos aspectos quantitativos e estatísticos do sucesso da inclusão educacional, pensar sobre a qualidade formativa que essa política deveria ter no que tange à constituição de cidadãos emancipados e críticos. Pensando a educação emancipatória, Adorno (2000) esboça a seguinte definição:

A seguir, e assumindo o risco, gostaria de apresentar a minha concepção inicial de educação. Evidentemente não a assim chamada modelagem de pessoas, porque não temos o direito de modelar pessoas a partir do seu exterior, mas também não a mera transmissão de conhecimentos, cuja característica de coisa morta já foi mais do que destacada, mas a produção de uma consciência verdadeira. [...] Numa democracia, quem defende ideais contrários à emancipação, e, portanto, contrários à decisão consciente independente de cada pessoa em particular, é um antidemocrata, até mesmo se as ideias que correspondem a seus desígnios são difundidas no plano formal da democracia. (p. 141-2)

Neste sentido, a situação do aluno surdo é bastante delicada. No Brasil, às divergências calorosamente debatidas nos últimos quinze anos em torno de qual língua deve ser utilizada na educação da pessoa surda (português oral e/ ou Língua Brasileira de Sinais), somam-se, mais nos últimos dez anos, as questões referentes ao tipo de escola mais adequada para este público com duas grandes fortes correntes: a educação bilíngue para surdos e a escola inclusiva para todas e todos.

Para autores como Gonçalves Filho (1998) e Chaui (2001), a compreensão das manifestações da subjetividade contemporânea necessita de uma análise da situação atual inserida em um processo histórico e social. Deste ponto de vista, compreende-se uma indissociabilidade intrínseca entre o indivíduo e seu ambiente - a cultura. Ao expandir tais conceitos e relacioná-los à psicanálise winnicottiana, temos que as possibilidades pessoais de manifestação genuína e criativa encontrariam no próprio ambiente o seu alimento e seu palco. Com isso, para que um desafio com o qual os profissionais da educação têm-se deparado cada vez mais frequentemente, qual seja, o da formação da pessoa surda, possa ser compreendido de forma não simplista, há a necessidade de uma reflexão sobre as condições concretas e historicamente construídas em torno deste público.

A pessoa surda a ser entendida no presente texto é aquela com uma perda auditiva bilateral significativa, majoritariamente severa ou profunda, instaurada antes, durante ou alguns anos após o seu nascimento. O foco recai sobre pessoas com este tipo de perda por ser ela aspecto de significativo valor no modo de subjetivação destes indivíduos, ou seja, nestas situações a perda auditiva é fator determinante e a partir do qual o indivíduo irá relacionalmente estruturar seu psiquismo, não sendo um mero fator periférico/acessório.

Como perda orgânica, segundo Northern e Downs (1991), as deficiências auditivas severa e profunda são de tal forma graves que impedem ou prejudicam significativamente a aquisição da linguagem na modalidade oral-aural, no caso do Brasil, a Língua Portuguesa falada. Para Sacks (1998), há um risco de tais pessoas permanecerem com sérias dificuldades de compreensão, pois a informação linguística que a pessoa surda comumente tem acesso nestes momentos encontra-se muitíssimo limitada. Ainda segundo este autor, tal tipo de dificuldade é "[...] uma das calamidades mais terríveis, porque é apenas por meio da língua que entramos plenamente em nosso estado e cultura humanos, que nos comunicamos livremente com nossos semelhantes, adquirimos e compartilhamos informações." (p. 22). Caso isso seja ignorado, "[...] ficaremos incapacitados e isolados, de um modo bizarro - sejam quais forem nossos desejos, esforços e capacidades inatas. E, de fato, podemos ser tão pouco capazes de realizar nossas capacidades intelectuais que pareceremos deficientes mentais" (p. 22). 
Durante a história, diferentes olhares e práticas incidiram sobre as pessoas que se encontravam neste tipo de situação. As propostas educacionais resultantes estruturaram-se tanto pelas visões de homem/mundo presentes em determinada época quanto de pessoa surda (Botelho, 1998; Souza, 1995). De ignorados passaram, a partir do século XVI até os dias de hoje, a ser objetos de salvação piedosa, ainda sem espaço ativo de opinião e deliberação. De alunos minimamente educáveis por meio da alfabetização visual e de um certo esforço para adquirir a língua oral, passaram a ser reabilitáveis/tratáveis oralmente ou treináveis visualmente. Neste tempo, houve o reconhecimento, em maior ou menor grau, das chamadas línguas de sinais.

Mantendo o intuito de desvelar aquela camada estereotipada a que é preciso se opor, é importante destacar que, diferentemente das línguas de modalidade oro-aural como, por exemplo, o francês, o português ou o árabe, as línguas de sinais possuem uma gramática distinta por serem de uma modalidade linguística espaço-visual, ou seja, são produzidas no espaço por meio do movimento do corpo - com ênfase nas expressões faciais e nas mãos - e captadas visualmente. De fato, são idiomas usados por muitos surdos precoces por ser de fácil e rápida aquisição por estes e, também, por algumas pessoas ouvintes em contatos com surdos precoces, podendo expressar, segundo Sacks (1998), quaisquer ideias e sentimentos. Diferentemente de uma comum concepção estereotipada, não são gestos puramente transparentes ou imitativos, mas línguas ricas em nuances e possibilidades, produzidas regionalmente, assim como foram as distintas línguas orais. Em nosso país, o idioma visuoespacial utilizado por boa parcela das pessoas surdas precoces é a Língua de Sinais Brasileira (Libras). O grupo das línguas de sinais é composto, segundo Sacks (1998), por:

[...] todas as linguagens de sinais nativas, passadas e presentes (por exemplo, a Língua Americana de Sinais, a Francesa, a Chinesa, a lídiche, a antiga Língua de Sinais do Condado de Kent). Excluem-se, porém, as formas sinalizadas de linguagens faladas (por exemplo, inglês em sinais), que são meras transliterações e carecem da estrutura das línguas de sinais genuínas. (p. 9-10).

Durante a maior parte do século XX, no Brasil, a modalidade predominante na Educação de surdos foi a de escolas especiais oralistas nas quais havia um esforço de transformar os alunos em pessoas adaptadas para a comunicação majoritária oral. Neste processo médico-educacional, tornou-se comum que as pessoas surdas pouco aprendessem, implicando graves marcas emocionais e formativas (Luz, 2003). A partir da década de 1990, muitos surdos, pelo mundo todo, começaram a relatar suas experiências educacionais como forma de denunciar uma visão estreita a respeito da pessoa surda. Como exemplo, Mason (1991) relata:

Eu lembro de me sentir completamente fora de o que quer que estivesse acontecendo à minha volta na escola. Meus olhos não estavam sendo usados para o seu potencial, e a informação era empurrada para meus ouvidos. [...] O pai e a mãe de Clark eram ambos surdos. Isto realmente teve um efeito em mim já que eu sempre tive uma completa barreira linguística entre eu e o mundo adulto. [...] Eu frequentemente ia para a casa de Clark depois daquilo e, através das conversas com a mãe e o pai de Clark, a minha confiança elevou-se. Era como se minha educação sobre o mundo estivesse finalmente começando, algo que a escola nunca foi capaz de fazer ${ }^{3}$ (p.86-7).

Durante a década de 1990, o movimento político da comunidade surda brasileira simpatizante da Língua Brasileira de Sinais (Libras) ganhou força e reclamou com veemência pela legitimação da mesma, assim como por escolas que oferecessem a Libras como idioma de instrução e ensinassem a Língua Portuguesa escrita como segunda língua. Foi somente em 2002 que a Libras foi legitimada como uma língua através da Lei Federal $n^{\circ}$. 10.436 de 24 de abril. Segundo esta lei:

Art. $1^{\circ}$. É reconhecida como meio legal de comunicação e expressão a Língua Brasileira de Sinais - Libras e outros recursos de expressão a ela associados. Parágrafo único. Entende-se como Língua Brasileira de Sinais - Libras a forma de comunicação e expressão, em que o sistema linguístico de natureza visomotora, com estrutura gramatical própria, constituem um sistema linguístico de transmissão de ideias e fatos, oriundos de comunidades de pessoas surdas do Brasil.

Em seu segundo artigo, a mesma lei afirma que:

Deve ser garantido, por parte do poder público em geral e empresas concessionárias de serviços públicos, formas institucionalizadas de apoiar o uso e difusão da Língua Brasileira de Sinais - Libras como meio de comunicação objetiva e de utilização corrente das comunidades surdas do Brasil.

Justamente a fim de garantir a efetivação do aspecto multiplicativo da Libras e a regulamentação da Lei Federal no. 10.436, entrou em vigor, em 22 de dezembro de 2005 , o Decreto Federal $n^{\circ}$. 5.626. Se, no aspecto social, há uma promessa de inserção da Libras no cotidiano social e educacional brasileiro, a realidade frequente das pessoas surdas ainda é definida por seus familiares e os profissionais - ou as políticas públicas - que discursam sobre a pessoa surda, mantendo-a na condição de objeto da ação de outrem, e buscando muitas vezes ainda sua reabilitação orgânica. Em outras palavras, a surdez precoce é, frequentemente, vista em nossa sociedade como uma marca demeritória, a qual leva ao olhar estigmatizante que atravessa negativamente a própria constituição da pessoa surda. Segundo Gonçalves Filho (1998, p. 49), "[..] se há algo de poderoso nos fatos de reificação é que, não apenas fazem funcionar como coisa

3 Tradução dos presentes autores. 
quem é humano, mas tendem a obscurecer a visão de que a coisa ali, é na verdade um homem" . ${ }^{4}$

Pensando no aspecto educacional, se por um lado há toda uma complexa discussão sobre a língua mais efetiva na instrução de pessoas surdas - e parece forte a possibilidade emancipatória que a real aquisição da língua de sinais pode oferecer, apesar de não ser garantia certa de formação e saúde psíquica -, tem ganhado espaço, nos últimos dez anos, toda uma rica proposta de uma sociedade menos segregacionista através da Educação Inclusiva. No entanto, há frequentes queixas de pais e alunos surdos, assim como da comunidade surda, sobre a garantia que esta proposta educacional oferece de uma primeira língua acessível à pessoa surda, já que esta criança chega à escola, na grande maioria das vezes, com sérias limitações comunicativas, fruto de uma sociedade ainda excludente. Assim, um aspecto importante, com sérias implicações na construção de políticas educacionais adequadas a esta parcela da população, é sobre a própria aquisição destas línguas.

\section{A escola em que vivemos}

Recuando em direção à história da Educação, principalmente, à Educação destinada a pessoas surdas, a marca que encontramos é a da segregação, da relação rápida e leviana entre surdez e déficit cognitivo, o que justificaria, então, o predomínio do assistencialismo e de objetivos de formação de mão de obra pouco ou nada qualificada. Recuando em direção à história da condição social de pessoas com deficiência, chegamos a situação muito semelhante: inferiorização, humilhação dos sujeitos, que frequentemente ainda são vistos como criaturas, ora tocadas por Deus, ora pelo demônio, mas sempre fora do campo do humano (Amaral, 1994).

Gonçalves Filho (1998) relembra-nos uma lição de Simone Weil: quando não há possibilidade de nos reconhecermos no campo social, em meio a outros homens, perdemos nosso vínculo com o passado, o presente e o futuro; nosso fazer torna-se algo em si, com a única função de garantir, por mais alguns momentos, a continuidade da reprodução da vida abstrata.

Tendo em vista a máxima freiriana (Freire, 2000) de que não há a educação em si, mas que os homens educamse uns aos outros, em comunhão, uma possível contribuição da Psicologia seria atentar para o fenômeno do impedimento da realização dos objetivos educacionais, sua lógica, seus sentidos, seus protagonistas. Não o tomar como unicamente psicológico, não decodificar, dividir ou sistematizar simplesmente, mas compreendê-lo em sua positividade. Não se trata de defender uma educação igual para todas e todos, pelo contrário: trata-se de discutir, em conjunto, como garantir igualmente o direito à Educação para o sujeito humano, tomado como necessariamente plural.

E o que deforma na escola de hoje?

Alguns afirmam ser o elitismo do saber, que acaba por destinar às massas um aprendizado técnico-instrumental,

4 Grifos do texto original. voltado para a realização do trabalho manual. Mas a realidade atual mostra-nos a ausência até do conhecimento voltado para a técnica, para o pragmatismo. Patto (2000a) afirma que grande parte do alunado, hoje, não tem sequer acesso àquilo a que Adorno chamou de semiformação.

Há também aqueles que imputam ao ensino da subalternidade o caráter deformador da escolarização. Entretanto, no caso da educação de surdos, acompanhamos um processo mais radical: a experiência da dominação como o posicionamento do outro em um não lugar, porque, afinal, o sujeito surdo, ao não se submeter ao padrão de comunicação via língua oral-aural, adquire o estigmatizante estatuto de incapaz de comunicação e linguagem. Enfim, sua posição é a de quem está fora do universo humano.

\section{O lugar com que precisamos sonhar}

Em uma perspectiva winnicottiana (Winnicott, 1975, 2000), o encontro entre os homens é aquilo que constitui a humanidade mesma. Os vários momentos pelos quais esse encontro passa, desde a relação cuidador/bebê até a mútua dependência, podem ser demonstrativos do quanto o homem forja-se nas várias modalidades que a relação com o outro comporta. O tempo subjetivo e o tempo transicional revelam elementos do jogo de apresentação, manipulação e apropriação do mundo para que, enfim, possa-se compartilhar a experiência de estar no mundo com o outro.

Esta psicanálise, portanto, trata dos processos de reconhecimento e não reconhecimento da humanidade em nós, por meio da experiência com o outro, que nos permite criar o que já está ali. Para isso, é necessário que nos identifiquemos, que possamos sonhar que o outro diante de nós é um igual, é gente como a gente.

Outro aspecto relevante no processo de constituição da subjetividade refere-se à possibilidade de realização de experiências e de acesso a objetos culturais a elas relacionados; objetos que sejam significativos, que tenham sentido, mais do que tudo, que revelem a existência do humano no mundo e que apóiem o sentimento de existência de cada um de nós, com direito a passado e presente apoiando o ato de sonhar um futuro. Entre os objetos culturais, cabe destacarmos os objetos étnicos e os objetos transicionais, que são elementos fundantes desse sentimento (Safra, 2004). Os primeiros estão relacionados à história familiar do grupo cultural a que pertence o sujeito, ou seja, apontam para o entroncamento das várias vidas humanas que se concretizam nas inter-relações. Já os objetos transicionais apresentamse como a possibilidade de habitarmos o mundo: na medida em que se prestam a abrigar nossas produções imaginativas, permitem que tenhamos cada vez mais esperança na interlocução entre o que necessitamos, desejamos e o que a cultura tem a nos ofertar.

Porém, quando acompanhamos a produção daqueles que se debruçam sobre a questão da formação da identidade individual e grupal de pessoas surdas, encontramos, via de regra, relatos de experiências de impedimento da possibilidade de se reconhecer no outro e na cultura. Sua língua, suas 
formas expressivas de se comunicar, de produzir e reeditar sua compreensão de si e do mundo são raramente reconhecidas como legítimas no meio científico. Sob um espectro de argumentos que vai desde o rebaixamento da língua de sinais a uma sucessão de gestos empobrecedores da comunicação até a preocupação com as dificuldades de interação com os sujeitos falantes da língua majoritária - o português, no nosso caso -, profissionais da saúde e da educação acabam por transmitir aos pais, mais ou menos conscientemente, a ideia de que a pessoa surda está fora da comunicação, caso não faça adesão à língua majoritária. Diferentemente do estrangeiro, cuja língua forasteira, apesar de não conhecida, tem sua dignidade reconhecida, a pessoa surda, usuária da Libras, ocupa o lugar de alguém sem língua, posto que ainda prevalece o não reconhecimento da legitimidade da língua de sinais. Ao não considerar o direito à língua, ao não entender o surdo como sujeito humano, contribuímos para um dos maiores sofrimentos de todos, segundo Weil (1996): o de não ter reconhecida a legitimidade de seu sofrimento. $E$ a pessoa surda não tem a possibilidade de compreender que está sendo impedida de fazer disso uma experiência. Tudo acontece, mas não ganha caráter de experiência.

Em uma perspectiva winnicottiana, Freller (1999) entende a escola como elemento da cultura que constitui o humano em nós a partir de duas principais funções: "[...] participar da instauração e ampliação do espaço potencial e apresentar materiais culturais relevantes, de forma que o aluno possa se apropriar deles de forma criativa e singular, preservando sua identidade pessoal e grupal." (p. 195). A forma pela qual a escola tem contemplado o aluno surdo a ponto de permitir a sua apropriação efetiva do espaço escolar enquanto um espaço potencial constitutivo de sua singularidade humana e o quanto tem oferecido instrumentos comunicativos reais para a apropriação dos materiais culturais relevantes são, certamente, algumas das questões centrais ao se pensar o processo formacional da pessoa surda, tanto do ponto de vista educacional quanto psíquico, afinal a identidade de "escolar" compõe nossa subjetividade.

Nesse contexto, o papel da escola de surdos tem sido justamente o de proporcionar o sentimento, a experiência de um lugar possível no mundo, de uma identidade, com direito a uma língua própria, que viabilize e sustente a construção de um universo de trocas simbólicas, que tenha um fim em si mesmo. Este mesmo fenômeno gera outros efeitos, ainda por se explorar. Passamos a apontar aqui apenas alguns possíveis eixos:

Podemos pensar em efeitos junto aos pais, que veem seu filho utilizar-se de uma outra língua, sentir-se pertencente a um outro espaço, com outros costumes e modos de significar a si e ao mundo.

Há também que se pensar em quais têm sido os efeitos para a escola. Para além de seu objetivo geral, que é o de proporcionar o acesso ao conhecimento acumulado historicamente, a escola vê-se diante da responsabilidade de ofertar a experiência de viabilidade para esse sujeito que, como já afirmamos, vem constituindo-se como um "sem lugar". E é também por meio da escolarização que esse sujeito terá que encontrar na História os significados sociais para a marca da surdez, sempre atravessada pelo estigma da incapacidade, da inferioridade (Skliar, 1998).

Finalmente, podemos pensar quais são os efeitos para a pessoa surda propriamente. E, como toda experiência escolar, os desdobramentos são variados, intensos e bastante complexos. O que destacamos como prioritário é, enfim, a comunicação, por parte da escola, de um lugar para esse sujeito: um lugar em que ele tem acesso a uma forma de comunicação plena de sentidos e significados, bem como acesso à História, em que passado, presente e futuro podem articular-se mediante ação reflexiva. De forma sintética, tratase de um lugar em que o sujeito experimenta o pertencimento, a viabilidade de sua existência, sem que sua condição de surdo tenha que ser negada. Tal possibilidade, do ponto de vista winnicottiano (1975), é fundamental para o processo de humanização, posto que oferece esperança na interação com os outros. O problema que pode derivar para a pessoa surda é o sentimento de que apenas "lá", na escola, entre iguais, é que se pode existir.

Inúmeros dos estudiosos aqui citados, como Bueno (2004), Góes e Laplane (2004), Jannuzzi (2004) e Patto (2000a), sejam da Educação, sejam da Psicologia Escolar, têm apontado para o engodo presente na tentativa de compreensão dos fenômenos da Educação Especial sem relacioná-los à política educacional como um todo. Ora, se a escolarização que se oferece às pessoas com deficiência está remetida ao projeto de Educação em geral, é preciso, então, compreendermos quais são seus compromissos e como se concretizam na atual organização escolar. Tal projeto de Educação é apenas uma das facetas do projeto de sociedade hoje vigente, relacionado portanto, a valores e aspirações intrinsecamente relacionados ao modo de produção capitalista. Trata-se de uma concepção que acaba por repor a exclusão, dado que não se baseia no compromisso de superação dos problemas substantivos do sistema educacional brasileiro - a formação dos profissionais da educação, suas condições de trabalho e sua remuneração - mas tão somente na construção de competências e habilidades. Autores da Educação, da Psicologia e da Sociologia da Educação, em seus estudos, já revelaram que nosso sistema educacional, que se articula a um projeto econômico-político, organiza-se a partir de uma lógica que imputa ao indivíduo a responsabilidade por seu próprio percurso, sem questionar o mundo em que isso tudo aconteces.

O desafio de uma Educação Formativa para todas e todos incide justamente neste ponto: a escola - regular ou especializada - tal como hoje se organiza, não garante o sentimento de pertencimento ao universo humano a ninguém, basta que olhemos para os índices de desempenho escolar ou para o percentual de licenças-saúde por questões relativas ao adoecimento psíquico de educadores. Mas, se quisermos conhecer esse fenômeno profunda e complexamente, nada melhor que acompanharmos longamente a vida

5 A esse respeito, podemos citar Azanha (1987), Patto (2000) e Gentili (2007). 
diária de alunos e educadores em uma escola pública, por exemplo, como bem já nos ensinou Patto (2000a).

Há uma aparência de respeito às diferenças na forma como está estruturada a política pública educacional de inclusão. Porém, na medida em que propõe que as pessoas sejam atendidas em função das patologias que as diferenciam umas das outras, outra face é evidenciada, qual seja, a da desconsideração dos sujeitos concretos, que são irredutíveis a um diagnóstico, a uma sintomatologia ou mesmo a um traço psicossocial. Ao arrolar fragmentos de nossa humanidade como indicativos de funcionamentos discrepantes em relação à norma abstrata, tal política acaba por reiterar a possibilidade de um novo coletivo: o de anormais. Outras nomenclaturas podem ser utilizadas, como especiais, casos de inclusão e pessoas com necessidades especiais, mas a marca refere-se ao quanto tais fragmentos distam da normalidade.

Educação para todas e todos, necessariamente, implica uma Educação em que o direito à língua seja reconhecido, as especificidades tenham lugar. Posicionamonos, então, em nome de uma intervenção psicológica junto aos fenômenos da escolarização que se comprometa com a necessidade radical de se repensar a arquitetura, as relações, a proposição, a organização das atividades etc., sempre garantindo a possibilidade de experiência entre os sujeitos. Trata-se, por isso, de uma intervenção consciente e assumidamente política. Não há mais como endossarmos uma prática educativa homogênea, seriada, classificatória, compartimentada em salas de aula, regida por relações de dominação entre profissionais administrativos, educadores, familiares e alunos.

É urgente o trabalho conjunto, entre educadores, psicólogos, alunos e familiares, a fim de criarmos espaços de aprendizagem que sejam plurais, podendo variar segundo o objetivo elaborado coletivamente. Temos acompanhado escolas que se propõem a construir outros arranjos educativos, em que alunos de diferentes idades e com diferentes hipóteses sobre o conhecimento podem, a partir de um interesse em comum, unir-se na investigação de um determinado tema. Havendo outros objetivos em jogo, outros agrupamentos de alunos e professores podem realizar-se.

Nenhuma estrutura deve sobrepor-se às necessidades dos educandos, desde as escadas, passando pela fragmentação das disciplinas, até a organização em classes.

Uma importante contribuição da Psicologia pode estar na garantia de situações de encontro humano na instituição escolar, procurando, sempre, evidenciar o reconhecimento da diferença que, se não for traumático, leva a estranhamento. É necessário que, diante dessas situações de convivência com diferentes pessoas, possamos perguntar: Quem é esse que se apresenta a mim? De onde vem? Como é? Tais questões só podem ser examinadas a partir do estabelecimento de uma relação. Assim, de fato, realiza-se um encontro: não pela negação da alteridade e do incômodo, mas justamente pela sua consideração, que abre possibilidades de reflexão sobre a nossa própria identidade e sobre a diversidade de formas presentes na humanidade.
No caso da população surda, pode não haver consenso a respeito dos efeitos da escolarização em instituições inclusivas ou especializadas, mas sobre um aspecto não há controvérsia: os profissionais da Educação, onde quer que trabalhem, precisam de liberdade para criar e recriar os espaços e as estratégias de aprendizagem cuja finalidade seja proporcionar aos educandos - e a si mesmos - experiências de relações mais horizontais com o outro, esteja ele marcado pela diferença linguística; sensorial; orgânica; de idade; de estilo cognitivo; de pertencimento étnico, religioso, cultural ou socioeconômico. Aí, então, estaremos comprometidos genuinamente com a construção de uma formação educacional que possibilite ao sujeito o encontro com sua humanidade.

Fica a expectativa em torno da formação humanizadora de qualquer pessoa, inclusive a surda, e de que o poder da reificação que marca nosso cotidiano não vá além do obscurecimento do olhar, pois, segundo Gonçalves Filho (1998, p. 49), "a visão do homem pelo homem - esta experiência de que diante do outro não nos encontramos diante de matéria bruta ou de mero organismo - mantém seu caráter irredutível. Permanece latente. Em condições propícias, pode reavivar-se".

\section{Referências}

Adorno, T. W. (2000). Educação - para quê? Em T. W. Adorno, Educação e Emancipação (pp. 139-154). Rio de Janeiro: Paz e Terra.

Amaral, L. A. (1994). Conhecendo a Deficiência: em Companhia de Hércules. São Paulo: Robe.

Angelucci, C. B. (2002). Uma Inclusão Nada Especial: apropriações da política de inclusão de pessoas com necessidades especiais na rede pública de educação fundamental do estado de São Paulo. Dissertação de mestrado, Instituto de Psicologia, Universidade de São Paulo, São Paulo.

Angelucci, C. B. (2009). O Educador e o Forasteiro: depoimentos sobre encontros com pessoas significativamente diferentes. Tese de Doutorado, Instituto de Psicologia, Universidade de São Paulo, São Paulo.

Azanha, J. M. P. (1987). Alain ou a Pedagogia da Dificuldade. Em J. M. P. Azanha, Educação: alguns escritos. São Paulo: Nacional.

Botelho, P. (1998) Segredos e silêncios da educação dos surdos. Belo Horizonte: Autêntica.

Bisol, C. A., Simioni, J., \& Sperb, T. (2008). Contribuições da psicologia Brasileira para o estudo da surdez. Psicol. Reflex. Crit. [online], 21(3), 392-400. Recuperado: 17 dez. 2009. Disponível: http://www.scielo.br/scielo.php?script=sci_arttext\&pid=S0102$79722008000300007 \&$ Ing=pt\&nrm=iso 
Bueno, J. G. S. (1998). Surdez, linguagem e cultura. Cad. CEDES [online], 19(46), 41-56. Recuperado: $17 \mathrm{dez}$. 2009. Disponível: http://www.scielo.br/scielo.php?script=sci_arttext\&pid=S010132621998000300005\&lng=pt\&nrm=iso

Bueno, J. G. S. (2004). Educação Especial Brasileira: integração/ segregação do aluno diferente. São Paulo: EDUC

Carvalho, M. P. de. (2004). O fracasso escolar de meninos e meninas: articulações entre gênero e cor/raça. Cad. Pagu [online], 22, 247-290. Recuperado: 22 jun. 2010. Disponível: $<$ http://www.scielo.br/scielo.php?script=sci_arttext\&pid=S0104$83332004000100010 \&$ lng=en\&nrm=iso

Chaui, M. de S. (2001). O que é ideologia (2a. Ed.). São Paulo: Editora Brasiliense.

Decreto Federal n. 5.626 de 22 de dezembro de 2005. (2005). Regulamenta a Lei 10.436, de 24 de abril de 2002, que dispõe sobre a Língua Brasileira de Sinais - Libras, e o art. 18 da lei $n^{\circ}$ 10.098, de 19 de dezembro de 200. Brasília. 2005.

Dizeu, L. C. T. de B., \& Caporali, S. A. (2005). A língua de sinais constituindo o surdo como sujeito. Educ. Soc. [online], 26(91), 583-597. Recuperado: 17 dez. 2009. Disponível: <http:// www.scielo.br/scielo.php?script=sci_arttext\&pid=S010173302005000200014\&lng=pt\&nrm=iso

Freire, P. (2000). Educação como Prática de Liberdade. São Paulo: Paz e Terra.

Freller, C. C. (1999). Pensando com Winnicott sobre alguns aspectos relevantes ao processo de ensino e aprendizagem. Psicologia USP, 10(2), 189-203.

Gentilli, P. (Org.). (2007). Pedagogia da Exclusão: crítica ao neoliberalismo em educação. Petrópolis, RJ: Vozes.

Góes, M. C. R. de, \& Laplane, A. L. F de. (Orgs.). (2004). Políticas e Práticas de Educação Inclusiva. Campinas, SP: Autores Associados.

Gonçalves Filho, J. M. (1998). Humilhação social - um problema político em psicologia. Psicologia USP, 9(2), 11-67.

Jannuzzi, G. S. de M. (2004). A Educação do deficiente no Brasil: dos primórdios ao início do século XXI. Campinas, SP: Autores Associados.

Horkheimer, M., \& Adorno, T. W. (1985). Excurso I: Ulisses ou Mito e Esclarecimento. Em M. Horkheimer \& T. W. Adorno, Dialética do Esclarecimento: fragmentos filosóficos. Rio de Janeiro: Jorge Zahar.
Kupfer, M. C. M., \& Petri, R. (2000). Por que ensinar a quem não aprende?. Estilos da Clínica, 5(9), 109-117.

Lei 10.436, de 24 de abril de 2002. (2002). Dispõe sobre a Língua Brasileira de Sinais - Libras e dá outras providências. Brasília.

Luz, R. D. (2003). Violência psíquica e surdez - os caminhos de um (des)encontro. Espaço Informativo Técnico-Científico do Instituto Nacional de Educação de Surdos, 20, 3-21.

Mason, C. (1991). School Experiences. Em G. Taylor \& J. Bishop (Org.), Being Deaf: the experience of deafness. London: Open University.

Northern, J., \& Downs, M. P. (1991). Hearing in children (4a. Ed.). Baltimore, MD: Williams \& Wilkins.

Patto, M. H. S. (2000a). A Produção do Fracasso Escolar: histórias de submissão e rebeldia. São Paulo: Casa do Psicólogo.

Patto, M. H. S. (2000b). Mutações do Cativeiro: escritos de psicologia e política. São Paulo: Hacker/EDUSP.

Pereira, B. R. P., \& Nascimento, M. L. B. P. (Orgs.). (2006). Inclusão e Exclusão: múltiplos contornos da educação brasileira. São Paulo: Expressão e Arte.

Sacks, O. (1998). Vendo vozes: uma viagem ao mundo dos surdos. São Paulo: Companhia das Letras.

Safra, G. (2004). A Po-ética na clínica contemporânea. Aparecida, SP: Ideias \& Letras.

Saviani, D. (2005). Escola e Democracia: teorias da educação, curvatura da vara, onze teses sobre a educação política (37a. Ed.). Campinas, SP: Autores Associados.

Secretaria de Educação Especial. Ministério da Educação. Dados de matrícula. Recuperado: 13 abr. 2007. Disponível: www.mec.gov.br/ seesp/arquivos/pdf/brasil.pdf. Brasília. 2007.

Skliar, C. (1998). A surdez: um olhar sobre as diferenças. Porto Alegre: Mediação.

Souza, R. M. de. (1995). Educação especial, psicologia do surdo e bilinguismo: bases históricas e perspectivas atuais. Temas em Psicologia, 2, 71-87.

UNESCO. (1994). Declaração de Salamanca e linhas de ação sobre necessidades educativas especiais. Conferência Mundial sobre Educação para Necessidades Especiais: Acesso e Qualidade. Salamanca. 
Viégas, L. de S., \& Angelucci, C. B. (2006). Políticas Públicas em Educação: uma análise crítica a partir da psicologia escolar. São Paulo: Casa do Psicólogo.

Weil, S. (1996). A vida e a Greve dos Metalúrgicos. Em S. Weil, A Condição Operária e Outros Estudos sobre Opressão (E. Bosi, Org.). Rio de Janeiro: Paz e Terra.
Winnicott, D. W. (1975). O Brincar e a Realidade. Rio de Janeiro: Imago.

Winnicott, D. W. (2000). A Capacidade Para Estar Só. Em D. W. Winnicott, Da Pediatria à Psicanálise. Rio de Janeiro: Imago.

Recebido em: 21/05/2008 Reformulado em: 03/05/2010 (1 $\left.{ }^{\text {a }}\right)$

Reformulado em: 22/06/2010 (2a)

Aprovado em: 06/07/2010

\section{Sobre os autores}

Carla Biancha Angelucci (bianchaangelucci@gmail.com)

Universidade Presbiteriana Mackenzie,São Paulo - SP

Renato Dente Luz (denteluz@yahoo.com.br)

Universidade de São Paulo, São Paulo - SP

\section{Correspondência}

Carla Biancha Angelucci

Rua da Consolação, 930, prédio 38

CEP 01302-907 - Consolação - São Paulo - SP 